\title{
EDUCAÇÃO PERMANENTE EM SAÚdE E NO TRABALHO DE ENFERMAGEM: perspectiva de uma práxis transformadora
}

\author{
Luiz A nildo A nacleto da SILVAa, Fabiane FERRA Z ${ }^{\text {b }}$, M ônica M otta LIN ${ }^{c}$,
} Vânia M arli Schubert BACKE S ${ }^{d}$, Sandra M arcia Soares SCH M IDT ${ }^{e}$

\section{RESUMO}

T rata-se de uma reflexão teórica que tem por objetivo estimular os leitores a repensar o papel da educação permanente dos sujeitos-trabalhadores da saúde e de enfermagem na perspectiva do desenvolvimento individual e coletivo, por meio da práxis transformadora. Procurou-se fazer uma articulação reflexiva dos princípios da práxis transformadora apresentada pelo filósofo Adolfo Sánchez Vázquez com os preceitos de educação permanente em saúde e no trabal ho de enfermagem. T al articulação apresenta uma concepção educativa em prol da conscientização dos sujeitos-trabal hadores sobre as distintas contribuições pessoais, sociais, relacionais e institucionais que podem advir das diferentes formas de perceber e exercer a educação per manente em saúde e no trabal ho da enfer magem.

D escritores: E ducação continuada. Pessoal de saúde. Conscientização. Filosofia em enfermagem.

\section{RESUMEN}

Setrata de una reflexión teórica quetieneel objetivo de estimular los lectores a repensar el papel dela educación permanentede los sujetos-trabajadores de la salud y dela enfermería en la perspectiva del desar rollo individual y col ectivo a través dela praxis transformadora. H icimos una reflexión buscando articular los principios de la praxis transformadora presentado por el filósofo A dolfo Sánchez Vázquez con los preceptos de la educación permanente en salud y en el trabajo de la enfermería. Esta articulación presenta un concepto educativo en favor de la concienciación de los sujetos-trabajadores acerca de las distintas contribuciones per sonales, sociales, relacionales e institucionales que puederesultar de diferentes maneras de percibir y ejercer la educación permanente en salud y en el trabajo de la enfermería.

D escriptores: E ducación continua. Personal de salud. T oma de conciencia. F ilosofía en enfermería.

Título: E ducación permanente en salud y en el trabajo de enfermería: perspectiva deuna praxis transformadora.

\section{ABST RACT}

This is a theoretical reflection that aims to encouragereaders to rethink the role of permanent education of heal th and nursing subjects/ w orkers in the perspective of individual and collectivedevel opment through transfor mative praxis. Wetried to makea thoughtful articulation about principles of transfor mative praxis presented by the philosopher A dolfo Sánchez Vázquez with the precepts of permanent education in health and nursing work. This articulation presents an educational concept in favor of the subject-worker's aw areness about the distinct contributions of personal, social, relational and institutional arrangements that may result from different ways of perceiving and practicing permanent education in health and nursing work.

D escriptors: E ducation, continuing. H ealth personnel. A wareness. P hilosophy, nursing.

$T$ itle: Permanent education in health and nursing work: perspective of a transformative praxis.

\footnotetext{
a D outor em Enfermagem, Professor A djunto do D epartamento de Enfermagem do Centro de E ducação Superior N orte da U niversidade Federal de Santa M aria (U F SM ), M embro do G rupo de Pesquisa em E ducação em Enfermagem e Saúde (E DEN) do Programa de PósG raduação em Enfermagem da U niversidade Federal de Santa Catarina (PE N / U F SC), Pal meira das M issões, Rio G rande do Sul, Brasil.

${ }^{b}$ M estre em Enfermagem, D outoranda pelo PE N / U F SC, M embro do G rupo de Pesquisa EDE N / PE N / U F SC, Bolsista de D outorado do

Consel ho N acional de D esenvolvimento Científico e T ecnológico (CN Pq), F lorianópolis, Santa Catarina, Brasil.

'M estre em Enfermagem, D outoranda pelo PEN/ U F SC, M embro do Grupo de Pesquisa EDEN/ PE N / U F SC, Bolsista de D outorado da Coordenação de A perfeiçoamento de Pessoal de N ível Superior (CAPES), F lorianópolis, Santa Catarina, Brasil.

d D outora em E nfermagem, Professora A ssociada do D epartamento de Enfermagem e do PE N / U F SC, Líder do Grupo de Pesquisa ED EN / PE N / U F SC, Pesquisadora de Produtividade do CN P q, F lorianópolis, Santa Catarina, Brasil.

e D outora em Enfermagem, Enfermeira do H ospital U niversitário de Santa M aria (HU SM ) da U F SM , Coordenadora do Curso de Enfermagem da F aculdade Integrada Santa M aria (F ISM A), M embro do G rupo de Pesquisa E D E N / PE N / U F SC, Santa M aria, Rio G rande do Sul, Brasil.
} 


\section{INT RODUÇÃO}

A lógica da sociedade capitalista, na qual predominam as políticas neoliberais de mercado, define que os trabalhadores sejam cada vez mais qualificados, mais produtivos e gerem mais-valia às instituições. N estas, a configuração da organização dos serviços destina-se a estabelecer formas de controle dos trabalhadores, onde o processo de trabal ho é concebido a partir das atividades a serem realizadas, em que se busca produtividade com qualidade, economia e segurança.

A produção científica sobre trabal ho em saúde, em especial na área da enfermagem, tem-se estruturado emitindo críticas a esse modelo que percebe 0 trabal hador como objeto de busca de produtividade ${ }^{(1)}$. T ais concepções do processo de trabal ho procuram romper com o modelo assistencial hegemônico de saúde e de organização do trabaIho, com a introdução de novas formas de organização e relações mais flexíveis e participativas, que visam melhorar a qualidade dos serviços prestados e a satisfação dos sujeitos-trabal hador es (2).

N este contexto, a educação permanente em saúde e no trabal ho de enfer magem vem sendo referida como uma das formas pelas quais o trabaIhador de saúde pode ser valorizado no seu processo de trabalho, sendo concebida tanto a partir da lógica de macropolíticas ${ }^{(3)}$, quanto de micropolíticas do trabalho em saúde e em enfer magem ${ }^{(4,5)}$.

0 conceito de educação permanente em saúde foi inicialmente trabalhado na saúde pela Organização Pan-Americana de Saúde (OPAS), nas décadas de 1980 e 1990. A pós 2003, no Brasil, foi instituída como política pública, a qual é compreendida como "aprendizagem no trabalho, onde 0 aprender e 0 ensinar se incorporam ao cotidiano das organizações e ao trabal ho"(6). Sua concretização depende que os processos educativos dos trabalhadores da saúde tenham como objetivos a transformação das práticas profissionais e da própria organização do trabalho, sendo que pode ser considerada como orientadora das iniciativas de desenvolvimento dos sujeitos-trabalhadores e das estratégias de transformação das práticas de saúde ${ }^{(3,4,7)}$.

Para refletir os preceitos de educação permanente em saúde, na perspectiva de uma práxis criadora ou inovadora/ transformadora, estudouse a obra "F ilosofia da Práxis", de A dolfo Sánchez Vázquez ${ }^{(8)}$, e os princípios atuais da educação permanente relacionados aos trabalhadores da área da saúde, com o intuito de aproximar tais referenciais, apontando possibilidades de como esta concepção educativa pode provocar mudanças a partir do pensar e do fazer dos sujeitos por meio de uma práxis transformadora.

A práxis é apresentada, na referida obra, em diferentes níveis: práxis criadora ou inovadora/ transformadora; práxis espontânea e reflexiva; práxis reiterativa ou imitativa. Os critérios para a análise desses níveis referem-se ao grau de criação demonstrado pelo produto de sua atividade e o grau de consciência revelado pelo sujeito no processo prático(8).

A práxis criadora ou inovadora/transformadora é conceituada como uma ação que cria algo novo através da intervenção da consciência e da prática humana. N este nível, o grau de consciência é alto, busca-se a reflexão e a concepção do modo de criar. A práxis reflexiva é o primeiro passo para se atingir uma práxis criadora pois, teoricamente e no plano do discurso, os sujeitos sabem o que devem fazer para inovar, criar e mudar. Porém, no plano real, isso ainda não é factível, limitando-se a uma práxis espontânea, na qual o sujeito tem um nível de consciência presente, porém, reduzido sobre si mesmo e em relação ao processo social que 0 cerca(8).

A ação advinda da práxis reiterativa ou imitativa consiste em repetir ou imitar outra ação. Ela não produz uma nova realidade, pois o grau de consciência humana é limitado. Contudo, pode contribuir para ampliar a área do já criado, pois multiplica quantitativamente uma mudança qualitativa já produzida. Nesse nível de práxis, o processo e o produto podem ser determinados e previsíveis, pois o produto não é único, uma vez que pode ser repetido(8).

A ssim, o objetivo desta reflexão teórica é estimular os leitores a repensar o papel da educação permanente dos sujeitos-trabalhadores da saúde e de enfermagem na perspectiva do desenvolvimento individual e coletivo por meio da práxis transformadora.

\section{EDUCAÇÃO PERMANENTE EM SAÚDE NA PERSPECTIVA DE UMA PRÁXIS TRANSFORM ADORA}

A práxis na filosofia marxista é utilizada para designar uma atividade material de relação dial ética entre o ser humano e a natureza na qual 
o ser humano, ao transformar a natureza com seu trabalho, transforma a si mesmo eà sociedade, sendo que esta transformação encontra-se atrelada à capacidade de ação e reflexão dos sujeitos ${ }^{(8-10)}$. L ogo, essa atividade material é compreendida como uma ação objetiva e transformadora da realidade natural e social, e não como qualquer atividade subjetiva, puramente prática, pois "pelo fato de proporse objetivos, o ser humano nega uma realidade efetiva e afirma outra que ainda não existe. $M$ as os fins são produtos da consciência e, por isso, a atividade que eles gover nam é consciente"(8), efetivando-se na práxis, isto é, na ação-reflexão-ação(9).

N esta perspectiva, os princípios da educação permanente em saúde se estabelecem pela ação e reflexão da realidade vivida no cotidiano de serviços dos trabalhadores da saúde de modo a transformar a realidade ${ }^{(3,4)}$, na qual a interação entre teoria e prática deveria ocorrer como uma exigência. Ao contrário, a teoria esvai-se no discurso e a prática acontece pela primazia da ação. Na práxis criadora, só há uma unidade entre teoria e prática quando a prática se revela teoricamente e pode transformar a realidade. Assim, a verdadeira concepção de práxis transcende a concepção teórica pois, na prática, é que se efetiva como uma atividade social(8-10).

A educação permanente em saúde visa ao questionamento da "realidade e suas metas de pactos e acordos diversos que confor mam propostas e projetos potentes para mudar as práticas e operar realidades vivas, atualizadas pelos diferentes saber es e conexões, pela atividade dos distintos atores sociais em cena e pela responsabilidade com 0 coletivo". Tem por objetivo trabalhar com as equipes e não com os trabal hadores corporativamente organizados, ou seja, apresenta um enfoque multiprofissional e interdisciplinar ${ }^{(4)}$.

$\mathrm{N}$ este sentido, apresentam-se al gumas questões para reflexão: Como as instituições de saúde trabal ham suas ações de educação permanente em saúde? Estas ações são desenvolvidas a partir de uma práxis criadora?

$\mathrm{N}$ a perspectiva da transformação, a educação permanente em saúde transita no sentido contrário ao da reprodução. $\mathrm{Na}$ reprodução, procura-se reforçar o instituído, enquanto na transformação, busca-se romper paradigmas que são socialmente aceitos. Estas afirmações sugerem reflexões mais específicas para a área da enfer magem e, para tanto, apresentam-se as seguintes indagações: como a enfermagem, no seu trabalho vivo em ato, desen- volve as ações de educação permanente em saúde? Quais paradigmas são assumidos nessas ações: um paradigma de práxis criadora ou de práxis reiterativa? Na primeira, imagina-se que é impossível realizar ações por uma única área da saúde enquanto, na segunda, adota-se uma postura de desenvolver ações específicas da área, que podem modificar pontualmente alguns aspectos vividos. Entretanto, na maioria das vezes, apenas reitera a realidade estruturada, pois não analisa o contexto da realidade junto a outros sujeitos-trabalhadores da saúde.

Para ultrapassar o paradigma da ideologia para a ação, é importante que os sujeitos-trabalhadores das diferentes áreas da saúde despertem para a reflexidade e crítica, de modo a buscarem que, no seu processo de trabalho, Ihes seja proporcionada educação permanente em saúde, a qual os prepare para atuarem efetivamente a partir dos princípios da integralidade, da interdisciplinaridade e, por conseguinte, Ihes proporcione melhor qualidade de trabalho e de ações em saúde aos sujeitoscidadão do cuidado. Ainda, torna-se imprescindível que esta educação seja conduzida conforme a realidade das situações de trabalho, que seja desenvolvida coletivamente, de acordo com as necessidades sociais e ancorada nos preceitos da práxis transformador $a^{(3-5,7,8)}$.

$\mathrm{Na}$ concepção marxista, os sujeitos são produtos do seu próprio trabalho, porque este produz objetos e relações sociais com um caráter que pode ser alienante em ambos os $\operatorname{casos}^{(8)}$. N esta perspectiva, a libertação dos sujeitos ocorre quando o processo educativo, desenvolvido simultaneamente ao processo de trabalho, esteja voltado à desalienação dos trabalhadores. T al desalienação se efetiva a partir da ação e da reflexão, por meio de uma práxis que permita aos mesmos serem sujeitos de suas transformações, pois é transformando a si que se transforma a sociedade ${ }^{(8,9)}$.

D esse modo, em todas as áreas da saúde, inclusive na enfermagem, o processo de educação permanente em saúde transcende ao aperfeiçoamento técnico, ao possibilitar aos sujeitos-trabaIhadores buscarem sua autonomia, cidadania, bem como resgatar sua multidimensionalidade, a qual poderia constituir-se como fundamento de desalienação. Logo, o processo educativo pode se caracterizar como um cuidado das instituições para com os seus sujeitos-trabal hadores no processo de trabalho ${ }^{(1,5,10-12)}$. 
A educação permanente em saúde a partir de uma práxis criadora estabelece possibilidades de transformação, de visualização, de ampliação, de valorização dos conhecimentos do coletivo de sujeitos envolvidos no processo de trabal ho da área da saúde. T ambém, associados aos preceitos teóricos, busca integrar prática e teoria no processo educativo, criando um movimento dinâmico de fazer e refazer-se. Por conseguinte, a educação permanente em saúde pode ser compreendida como um dispositivo para a transformação, de modo que os sujeitos-trabalhadores da saúde se percebam como cidadãos e possam assumir maior controle sobre seu processo de trabal ho ${ }^{(10-12)}$.

Assim, a educação permanente em saúde de concepção transformadora apresenta-se como alternativa viável de superação da práxis reiterativa e reprodutiva de domesticação, de tecnicismo, de formas acríticas de fazer, com rotinização, compartimentação de saberes, treinamentos e adestramentos. Logo, ao ensaiar um desenho de educação permanente em saúde na perspectiva de uma práxis transformadora, busca-se rescindir com 0 usual e instituir novas maneiras de pensar/agir a educação como proposta de transformação pessoal, profissional, social e institucional. Para tanto, parte-se do ideário de repensar e introduzir ações educativas de modo a potencializar a participação dos sujeitos-trabalhadores em todas as fases do processo de trabal ho(4,5,11).

\section{CONSIDERAÇÕES FINAIS}

Portanto, a proposta de educação permanente em saúde na perspectiva de transformação ocorre através da articulação entre a teoria e prática realizada pelos sujeitos-trabalhadores, permeada por políticas institucionais que sustentem estas ações. N este sentido, visualiza-se que as possibilidades de mudanças através das ações de educação permanente em saúde podem constituir-se em formas alternativas de transcender aos modos tradicionais de educação ao preconizar-se atividades educativas inseridas no contexto histórico, social, econômico, político e ético.

A ênfase em uma práxis transformadora está em proporcionar aos sujeitos-trabalhadores a construção de conhecimentos fundamentados na liberdade individual e coletiva, ancorados nos preceitos de cidadania, situação que a transformação individual que possa incidir em transformações sociais.
Assim, o objetivo final desse manuscrito não foi definir respostas, mas sim, instigar os leitores a dialogar reflexivamente com seus pares sobre qual nível de práxis está sendo realizado nas ações de educação permanente em saúde desenvolvidas nas diferentes ár eas em suas instituições. E sperase que, com o que foi apresentado teoricamente nessa reflexão, seja possível incentivar tal diálogo.

\section{RE FERÊ NCIAS}

1 Ramos FRS, Bertoncini JH, M achado RR, Flor RC, Pires DEP, G elbcke FL. T rabal ho, educação e política em seus nexos na produção bibliográfica sobre 0 cuidado. T exto Contexto Enferm. 2009;18(2):361-8.

2 Campos G W S. Subjetividade e administração de pessoal: consider ações sobre os modos de gerenciar o trabal ho de equipe de saúde. In: M erhy EE, Onocko R, organizadores. A gir em saúde: um desafio para o pú-

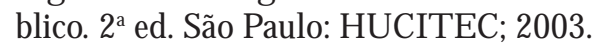

3 Ceccim RB. E ducação permanente em saúde: desafio ambicioso e necessário. I nterface Comun Saúde E duc. 2005;9(16):161-77.

4 M erhy EE, Feuerwerker LCM, Ceccim RB. E ducación permanente en salud: una estrategia para intervenir en la micropolítica del trabajo en salud. Salud Colect. 2006;2(2):147-60.

5 Ferraz F, Salum N C, Carraro T E, Radünz V, Espinoza LM M . E ducação permanente no trabal ho como um processo educativo e cuidativo do sujeito-cuidador. Rev G aúcha E nferm. 2006;27(3):344-50.

6 M inistério da Saúde (BR ), Portaria G M / M S n 1.996, de 20 de agosto de 2007: dispõe sobre as diretrizes para a implementação da Política $\mathrm{N}$ acional de E ducação Per manente em Saúde [ Internet] . Brasília (D F); 2007 [ citado 2010 mar 10]. Disponível em: http:/ / dtr2001.saude.gov.br/ sas/ PORTARIA S/ Port2007/ G M / G M -1996.htm.

7 Davini M C, N ervi L, Roschke M A. Capacitación del personal de los servicios de salud: proyectos relacionados con los procesos de reforma sectorial. Quito: Organización Panamericana de Salud; 2002. (O bservatorio de Recursos Humanos de Salud; 3)

8 Vázquez AS. Filosofia da práxis. São Paulo: Expressão Popular; 2007.

9 Freire P. Pedagogia da autonomia: saberes necessários à prática educativa. 31ạ ed. São Paulo: Paz e T erra; 2005. 
10 Backes VM S, Schmidt SM S, N ietsche EA, Saurin M H G, Ferraz F. E ducação continuada: algumas considerações na história da educação e os reflexos na enfermagem. Texto Contexto Enferm. 2003;12(1):80-8.

11 Silva LAA . Per spectivas de transcender na educação no trabalho: tendências da enfer magem latino-ame- ricana [ tese] . Florianópolis: U niversidade Federal de Santa Catarina; 2007.

12 Rical doni CAC, Sena R R . E ducação per manente: uma ferramenta para pensar e agir no trabalho de enfermagem. Rev Latino-Am Enfermagem. 2006;14(6): 837-42.
E ndereço do autor / Dirección del autor / Author's address:

L uiz A nildo A nacleto da Silva

Rua Antonio Boenig, 268, M orada do Sol

98700-000, Ijuí, R S

E-mail: luiz.anildo@yahoo.com.br
Recebido em: 08/ 04/ 2010

A provado em: 19/08/ 2010 